\title{
ANÁLISE DO DESMATAMENTO NA APA SERRA BRANCA/RASO DA CATARINA EM JEREMOABO - BA.
}

\author{
Luana Brito Limaㄹ, Hermilino Danilo Santana de Carvalho \\ ${ }^{1}$ Bacharelanda em Geografia, UEFS, Feira de Santana-BA, luaanabritoo@gmail.com \\ ${ }^{2}$ Geógrafo, Professor do Depto. De Ciências Humanas e Filosofia, UEFS, Feira de Santana- \\ BA, hdscarvalho@gmail.com
}

PALAVRAS-CHAVE: vegetação, APA, sensoriamento remoto

\section{INTRODUÇÃO}

Para o IBAMA (Instituto Brasileiro do Meio Ambiente e dos Recursos Renováveis), o desmatamento é a operação que tem como objetivo a supressão total da vegetação nativa de determinada área para o uso alternativo do solo. Considerando como sendo nativa, toda vegetação original, remanescente ou regenerada. A exposição da superfície do solo pela redução da cobertura vegetal é o fator desencadeante do processo erosivo. Para Jesus e Silva (2012) é importante ressaltar que a ação humana vem atuando com muito mais intensidade no meio ambiente, sendo um dos principais responsáveis pelo aumento do fenômeno da desertificação, que é um dos principais problemas ambientais ocorrentes na região de Jeremoabo. Por outro lado, desde 2000 foi aprovada e regulamentada a lei que instituiu a criação das APAs (Área de Proteção Ambiental), o objetivo é a conservação dos processos naturais e da biodiversidade, através da orientação, desenvolvimento e adequação das atividades humanas às características naturais do ambiente. Para verificação do desmatamento um dos métodos mais utilizados é o NDVI, através do uso de imagens de satélite e técnicas de sensoriamento remoto. Melo et al. (2011) afirmam que o Índice de Vegetação por Diferença Normalizada (NDVI) é uma aplicação dos processos de realce por operação entre as bandas de sensores de satélites no qual são importantes para ressaltar a avaliação do comportamento da cobertura vegetal. Gallego (2004) diz que as técnicas de regressão estatística, os softwares utilizados nas análises de imagem e os Sistemas de Informações Geográficas (SIG) podem ser aplicados para monitorar e prever as evoluções espaciais e temporais da superfície. Assim, o principal objetivo desse trabalho foi analisar a evolução do NDVI como indicador da ocorrência de desmatamento na APA Serra Branca/Raso da Catarina no município de Jeremoabo - Bahia. E os objetivos específicos são: avaliar o comportamento do NDVI da área da APA no ano de 2009 em comparação ao ano de sua criação 2001; verificar a evolução da cobertura vegetal para identificar possíveis ocorrências de desmatamento na APA e suas causas e consequências.

\section{MATERIAIS E MÉTODO:}

A APA Serra Branca/ Raso da Catarina foi criada pelo decreto estadual $\mathrm{n}^{\circ} 7.972$, em 5 de junho de 2001 e está localizada no município de Jeremoabo, no Nordeste da Bahia, exatamente numa região denominada de Raso da Catarina. A APA está limitada ao sul pelo rio Vaza-Barris e ao norte pela Reserva Ecológica Raso da Catarina, administrada pelo IBAMA. Está inserida no clima semiárido, em uma das regiões mais secas da Bahia, com temperatura média de $27^{\circ}$ e com regime pluviométrico caracterizado por chuvas irregulares, perfazendo um total em torno de $400 \mathrm{~mm}$ ao ano. Toda a área é coberta de vegetação da caatinga, compostas por cactáceas, palmeiras e bromeliáceas e outras plantas xerófitas. (INEMA-BA). 


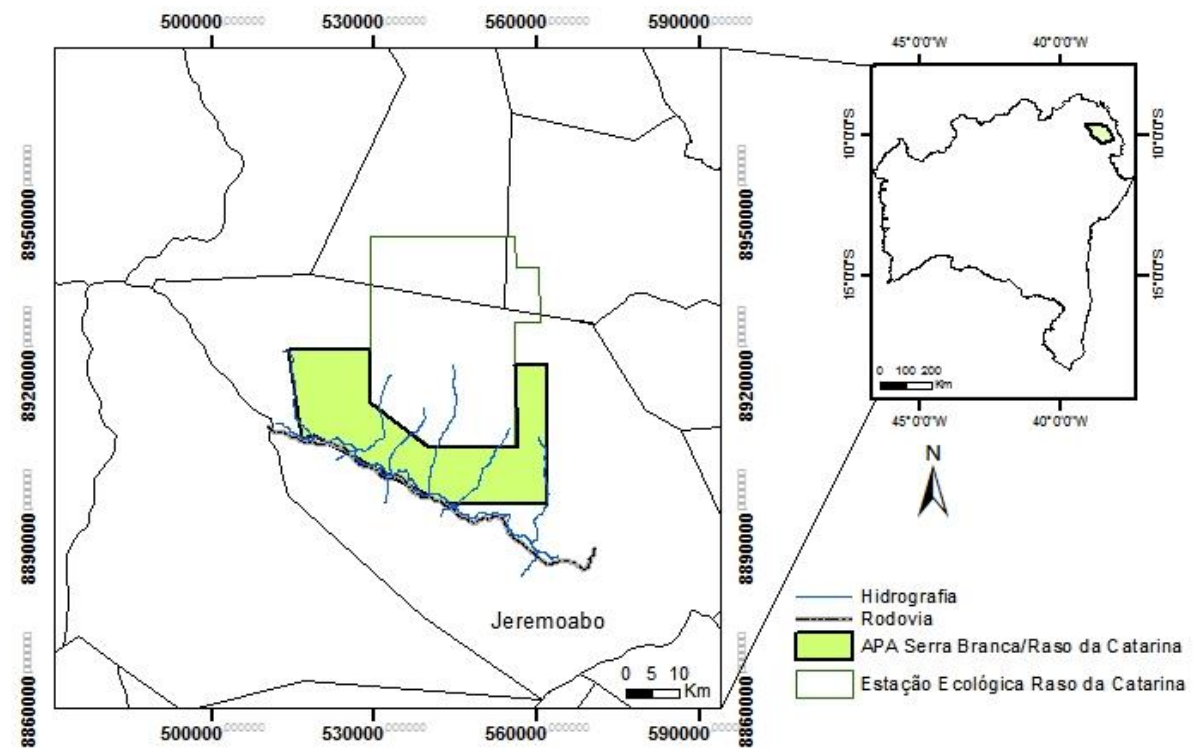

Figura 1- Localização da APA Serra Branca/Raso da Catarina, Jeremoabo - BA.

Para a realização desta pesquisa foram adotados os seguintes procedimentos metodológicos:

1. Revisão bibliográfica sobre os temas que permeiam essa pesquisa e sobre as características da área pesquisada.

2. Avaliação da vegetação, a partir das imagens referentes aos anos de 2001 e 2009, ambas referentes aos períodos seco e chuvoso, sendo essas imagens obtidas a partir do satélite LANDSAT 5, sensor TM, com a utilização do método do cálculo do NDVI (Índice de Vegetação da Diferença Normalizada), utilizando o software Quantum GIS. O Índice da Vegetação por Diferença Normalizada (NDVI) é um modelo resultante da combinação dos níveis de reflectância em imagens de satélites, que provem da equação composta pelas respostas das bandas espectrais do vermelho e infravermelho:

Em que:

$$
\text { NDVI = (NIR - R }) /(\text { NIR + R })
$$

NDVI é o índice de Vegetação por Diferença Normalizada;

NIR é a refletância no comprimento de onda correspondente ao Infra-Vermelho Próximo $(0,76$ a $0,90 \mu \mathrm{m})$;

$\mathrm{R}$ é a refletância no comprimento de onda correspondente ao Vermelho $(0,63$ a $0,69 \mu \mathrm{m})$.

3. Analise os resultados obtidos, utilizando os mapas produzidos em ambiente SIG para comparação visual, e a partir disso verificar evolução da cobertura vegetal e a ocorrência de desmatamento na APA.

\section{RESULTADOS E DISCUSSÃO:}

Observou-se que a vegetação do perímetro correspondente a APA Serra Branca/Raso da Catarina sofre com muita alteração entre o período de chuvas que vai de Dezembro a Junho, e o período de seca de Julho a Novembro, sendo que no período seco ela diminui bastante, comportamento esperado para uma área de vegetação caatinga. A vegetação sofre mais alteração na área central e a porção oeste. Fazendo uma análise comparativa entre as imagens do período chuvoso de 2001(Figura2) e 2009 (Figura3), verifica-se que o índice de cobertura vegetal aumentou em maior parte da APA, chamando a atenção para a área em torno do Rio Vaza-Barris. 

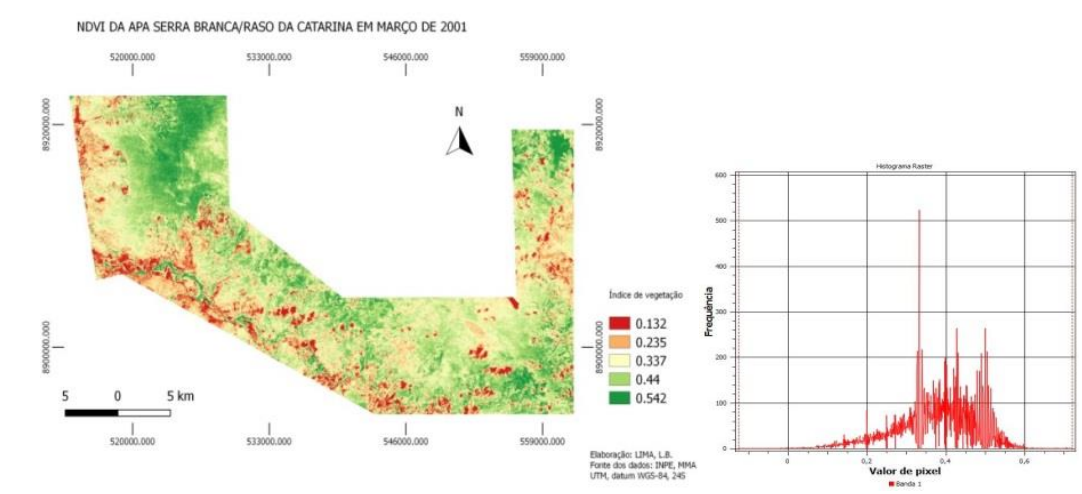

Figura 2 - NDVI da área da APA Serra Branca/Raso da Catarina e seu respectivo histograma, referentes ao período chuvoso em 2001.

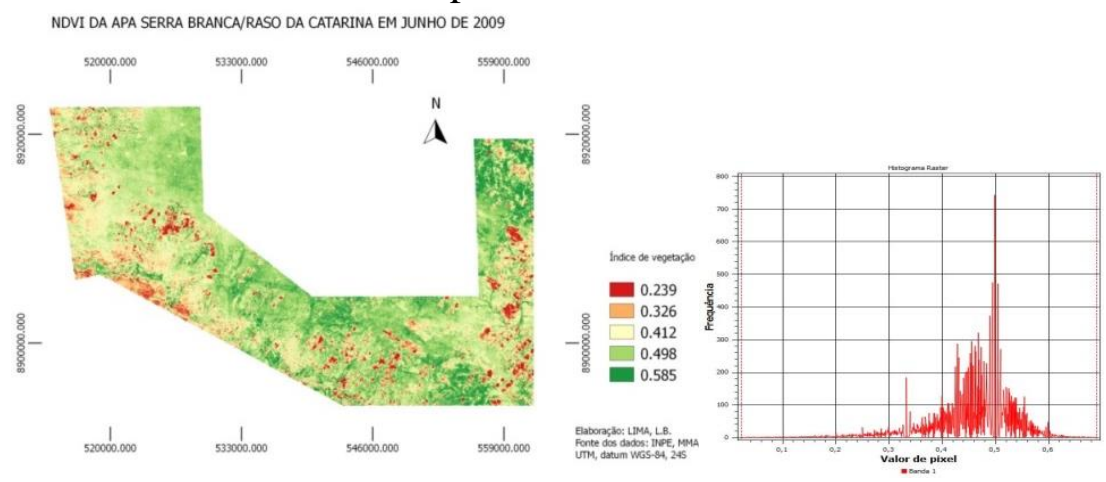

Figura 3 - NDVI da área da APA Serra Branca/Raso da Catarina e seu respectivo histograma, referentes ao período chuvoso em 2009.

E na a análise comparativa entre as imagens do período seco de 2001(Figura 4) e 2009 (Figura 5), observou-se que houve um leve aumento da vegetação na porção leste da APA, e novamente verificou-se a aumento da vegetação na área em torno do Rio Vaza-Barris.

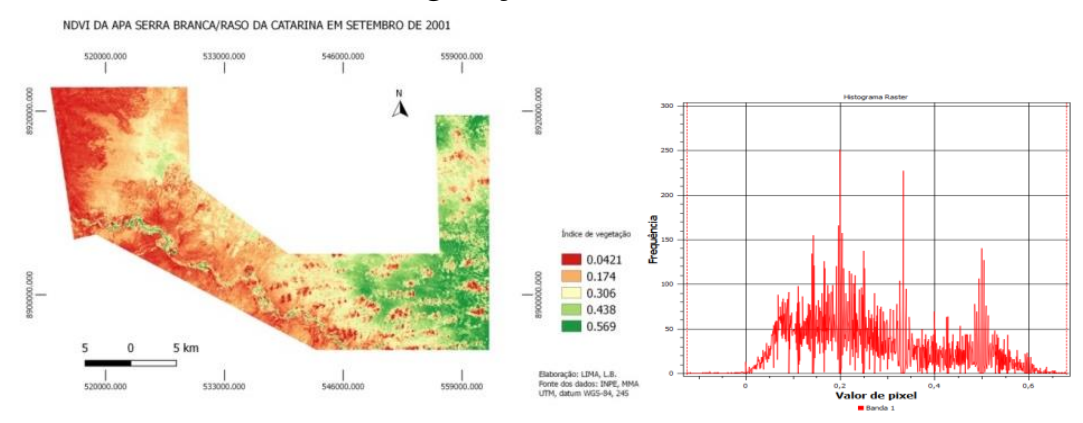

Figura 4 - NDVI da área da APA Serra Branca/Raso da Catarina e seu respectivo histograma, referentes ao período seco em 2001.

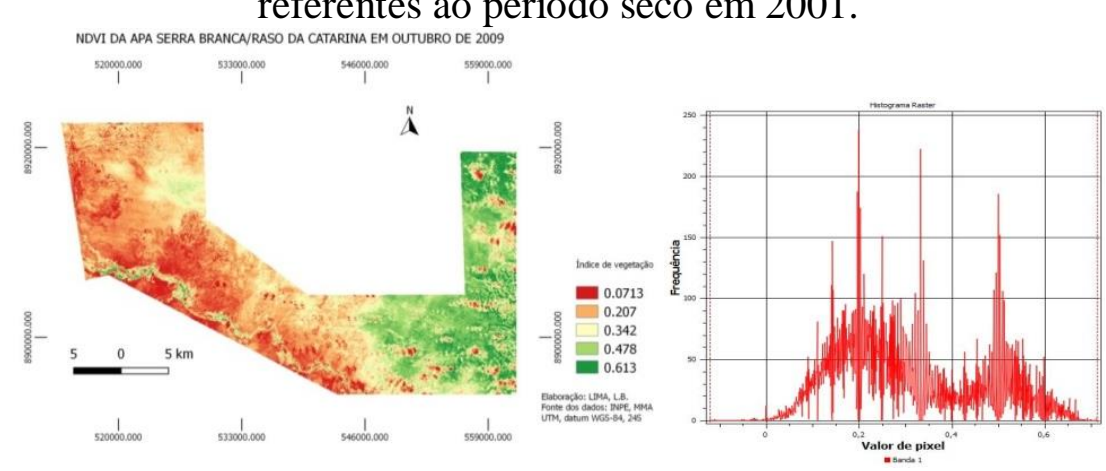

Figura 5 - NDVI da área da APA Serra Branca/Raso da Catarina e seu respectivo histograma, referentes ao período seco em 2009. 
A partir dessas verificações é possível inferir em uma discussão inicial que ao longo dos 8 anos passados entre a captação das duas imagens, de maneira geral, a área com cobertura vegetal aumentou, indicando que a implementação da APA foi importante para a recuperação de parte da área degradada. Por estar incluído em uma região com susceptibilidade aos processos de desertificação, aumentar as áreas com cobertura vegetal é importante para mitigar o avanço de tais processos que colocam em risco a biodiversidade e a sustentabilidade.

Porém é preciso indicar que ainda existem áreas com baixo índice de cobertura vegetal, mesmo no período chuvoso, o que indica que no ano analisado (2009) ainda ocorriam processos de desmatamento na área que compreende a APA Serra Branca/ Raso da Catarina, o que deve ser combatido com ações que visem melhorar a gestão da APA para garantir que cumpra o objetivo de preservação ambiental.

\section{CONCLUSÕES:}

A partir do que foi exposto nesse trabalho e da análise das imagens de satélite, com dados de 2001 a 2009, conclui-se que a criação da Área de Proteção Ambiental foi importante para preservação de grande parte da vegetação na região, até o ano analisado. Tal conclusão é justificada pelos esforços no sentido de fiscalizar que o uso das áreas incluídas na APA não interfira demasiadamente nas condições naturais presentes. Mas, ressalta-se que é necessário avançar nesses esforços, pois ainda existem áreas com pouco índice vegetativo dentro da APA. Por fim, é preciso destacar que esta foi uma pesquisa de caráter inicial e, portanto, fazem-se necessários mais estudos e observações em campo para verificar se a vegetação identificada é originária da região e quais são eventos que ocorrem na referida área que possuem algum potencial de degradação ambiental.

\section{REFERÊNCIAS:}

GALLEGO,F.J. Remote sensing and land cover area estimation. International Journal of Remote Sensing, Volume 25, Number 15, August 2004 , pp. 3019-3047

Instituto Brasileiro de Meio Ambiente e dos Recursos Naturais Renováveis. Disponível em: <http://www.ibama.gov.br/areas-tematicas/desmatamento> Acesso em 21/03/2017

Instituto do Meio Ambiente do Estado da Bahia. Disponível em: <http://www.inema.ba.gov.br/gestao-2/unidades-de-conservacao/apa/serra-branca-raso-dacatarina/> Acesso em 21/03/2017

JESUS, R.S. ; SILVA, E.S. Discutindo a problemática da desertificação. In: I Seminário Nacional de Geoecologia e Planejamento Territorial e IV Seminário do GEOPLAN, 2012, Sergipe. Anais... Sergipe: Universidade Federal de Sergipe, 2012.

MELO, E.T.; SALES, M L.S; OLIVEIRA, J.G.B. de. Aplicação do índice de Vegetação por Diferença Normalizada (NDVI) para análise da degradação ambiental da microbacia hidrográfica do riacho dos cavalos, Crateús-CE. Revista RA`E GA, n. 23, p.520-533, Curitiba, Departamento de Geografia - UFPR. 2011. 